\title{
Correlation of positive Bcl-2 expression with some clincopathological parameters in Iraqi colorectal cancer patients



Ahmed Rushdi Al-Dargazali

Biotechnology Research center / Al-Nahrain University

$$
\text { أحمد رشدي الاركزلي }
$$

مركز بحوث التقنيات الاحيائية|جامعة النهرين

\section{Abstract}

भुolorectal cancer is an important public health problem in Iraq. It's considered as the $7^{\text {th }}$ among the commonest 10 cancers by site according to the Iraqi cancer registry. Studying the Bcl-2 expression in colorectal cancer patients is one of the important issue for the prognosis of this tumor. In this study 50 colorectal cancer samples (paraffin embedded sections) were used to detect Bcl-2 expression using Immunohistochemical analysis. The correlation between Bcl-2 expression and site, type and grading was also studied. The results showed that there was a significant difference $(\mathrm{P}<0.05)$ in the $\mathrm{Bcl}-2$ expression between cancerous tissue and resection margin while the site, type and grading of the tumor showed generally the opposite data. We concluded that the positive Bcl-2 expression occurred at early stages of carcinogenesis and it's a voluble prognostic factor and target for therapy.

$$
\begin{aligned}
& \text { يعتبر سرطان القولون والمستقيم من المشاكل الصحية المهمة في العراق حيث يقع في المرتبة السابعة من }
\end{aligned}
$$

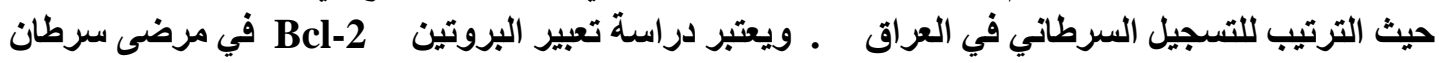

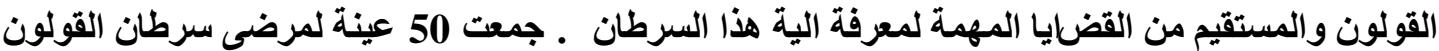

$$
\begin{aligned}
& \text { والمستقيم لدراسة تعبير بروتين ال }
\end{aligned}
$$

\section{Introduction}

Colorectal cancer is an important public health problem. There are nearly one million new cases of colorectal cancer diagnosed world-wide each year and half a million deaths [1]. In Iraq, it's the $7^{\text {th }}$ among the commonest 10 cancers by site according to the Iraqi cancer registry [2].

Reduction in the capacity of apoptotic cell turnover could be an important step in the development of neoplasia and one of its arms is $\mathrm{Bcl} 2$ which is a proto-oncogene located on chromosome 18q21 and codes $26 \mathrm{kd}$ protein that blocks apoptosis and rescues cells from death $[3,4]$.

Bcl-2 is a Cytoplasmic protein which can be seen in the mitochondria, endoplasmic reticulum, and the nuclear envelope. The protein can be identified in many different 
tissues, in follicular lymphomas, for example, the translocation t $(14 ; 18)$ results in constitutive overexpression of Bcl-2 and immortalization of lymphocytes [5].

Similarly, Bcl-2 overexpression has been identified in a large number of epithelial tumors like colorectal cancers which reported to show Bcl-2 overexpression [6]. Although, in comparison with adenomas, there is lower intensity of expression in the invasive tumors $[6,7]$.

There may also be a loss of expression with loss of tumor differentiation and it would appear that the role of Bcl-2 is probably more important in the early development of colorectal tumors than in later tumor progression [8].

The aim of this study is to correlate between positive bcl-2 expression and some histopathological parameters like: site, type and differentiation in Iraqi colorectal cancer patients.

\section{Materials and methods}

fifty colorectal cancer cases were collected from both digestive system diseases and liver teaching hospital and Baghdad teaching hospital in 2008.

Patients data were taken from the Histopathological reports that was written by a professional histopathologist which concern: site, type and differentiation of the tumor and resection margin which was the comparison to the cancerous tissues and confirmed to be free of malignancy.


margins were prepared on positively charged slides for the immunohistochemistry technique which was done by using anti Bcl-2 monoclonal antibodies from DAKO(Denmark) .

The streptavidin biotin indirect method was employed along with DAB (3 3'diaminobenzidine tetrahydroclorid) as chromogen and the sections were counterstained with hematoxylin. Cytoplasmic staining was accepted as positive for Bcl-2.

To define the ratio of positivity, 10 fields of each slide was studied under high power magnification (40x) and the percentage of Cytoplasmic positivity for Bcl-2 was graded as follows:

\begin{tabular}{cccc}
\hline marker & Negative $\%$ & Positive\% & Reference \\
Bcl-2 & $<10$ & $\geq 10$ & {$[5,9]$} \\
\hline
\end{tabular}

Statistical analysis was performed using ANOVA ( 2 way) with significant difference $(\mathrm{P}<0.05)$.

\section{Results}

Clincopathological data: The current study showed that left colon has the higher frequency and ten cases were mucinous type while three were signet ring and the rest of the fifty cases were adenocarcinoma. Most of the cases were graded as moderately differentiated. Other clincopathological data are shown in Table (1). 
Table (1): Clincopathological data of colorectal cancer patients.

$\begin{array}{cc}\text { Variables } & \text { Patients }(\mathbf{n}=\mathbf{5 0}) \mathbf{N}(\%) \\ \text { Site of tumor*: } & \\ \text { Right colon } & \mathbf{1 7}(34 \%) \\ \text { Left colon } & \mathbf{1 9}(38 \%) \\ \text { Rectum } & \mathbf{1 4}(28 \%) \\ & \\ \text { Tumor Type: } & \mathbf{3 7}(\mathbf{7 4 \%}) \\ \text { Adenocarcinoma } & \mathbf{1 0}(20 \%) \\ \text { Mucinous } & \mathbf{3}(6 \%) \\ \text { Signet ring } & \\ \text { Differentiation: } & \mathbf{4 ( 8 \% )} \\ \text { Well differentiated } & \mathbf{3 6}(\mathbf{7 2 \%}) \\ \text { Moderately differentiated } & \mathbf{1 0}(20 \%) \\ \text { Poorly differentiated } & \end{array}$

*Right colon: transverse, hepatic flexure, cecum and ascending colon. Left colon: splenic flexure, descending colon and sigmoid. Rectum: rectosigmoide and rectum.

\section{Bcl-2 positive Expression:}

There was a significant difference $(\mathrm{P}<0.05)$ in the positive of $\mathrm{Bcl}-2$ expression of the cancer tissue compared to resection margin Table (2), Figure $(1,2)$.

Table (2): The positive Bcl-2 expression of the cancer tissue compared to resection margin.

\section{Bcl-2}

Positive Expression

\section{Bcl-2 expression in cancerous tissue (mean+SE)}

$32.44 \pm 6.17$

A*
Bcl-2 expression in resection margin tissue $($ mean $+\mathrm{SE})$

14.82 \pm 1.28

Differences A, B are significant $(P<0.05)$ to compare rows.

Correlation between positive Bcl-2 expression and the site of the colorectal cancer site:

There was a significant difference $(\mathrm{P}<0.05)$ in the positivity of the Bcl-2 expression between the cancerous tissue and resection margin inside all colon and rectum anatomical sites except the descending colon which showed no expression in the transverse colon and splenic flexure Table (3).

Table (3) : The positive Bcl-2 expression in all anatomical sites.



Differences A, B are significant $(\mathbf{P}<0.05)$ to compare rows, ca: cancer; R.M.: resection margin. 
There was no significant difference $(\mathrm{P}<0.05)$ in positive $\mathrm{Bcl}-2$ expression of the cancerous tissue (compared with other sites) between the ascending colon, rectosigmoide and sigmoid. While the only significant difference $(\mathrm{P}<0.05)$ appeared in positive Bcl-2 expression of the resection margin were ascending and descending colon compared with the other anatomical sites Table (4)

Table (4) : The correlation between different anatomical sites and Bcl-2 positive expression.

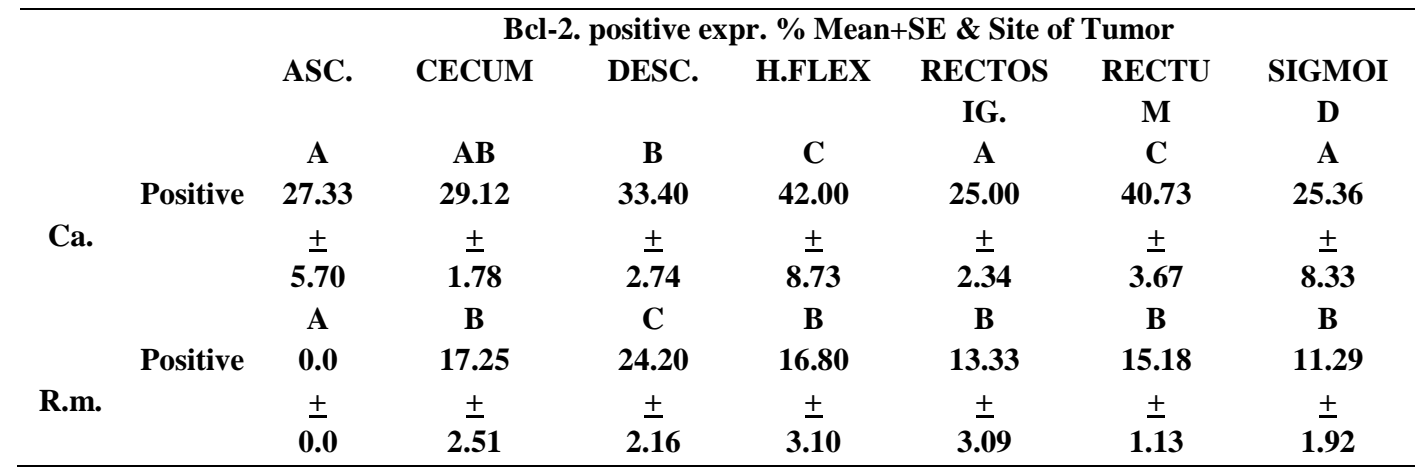

Differences A, B, AB \& $\mathrm{C}$ are significant $(\mathrm{P}<0.05)$ to compare rows, ca: cancer; R.M.: resection margin

Correlation between positive Bcl-2 expression and the colorectal cancer type:

There was a significant difference $(\mathrm{P}<0.05)$ in the positivity of the Bcl-2 expression between the cancerous tissue and resection margin inside all the 3 types presented in this study Table (5)

Table (5): The positive Bcl-2 expression in all types of colorectal cancer

Bcl-2 positive expr. \% Mean+SE \& Cancer type

\begin{tabular}{ccccccc} 
& AC & & \multicolumn{2}{c}{ MUCINOUS } & \multicolumn{2}{c}{ SIGNET RING } \\
Cancer & & R.marg & cancer & R.marg & cancer & R.marg \\
A $^{*}$ & & B & $\mathbf{A}^{*}$ & B & $\mathbf{A}^{*}$ & B
\end{tabular}

$\begin{array}{lllllll}\text { Positive } & 33.19 \pm 2.15 & 16.19 \pm 1.37 & 30.60 \pm 5.05 & 12.00 \pm 1.71 & 29.33 \pm 5.40 & 7.33 \pm 2.70\end{array}$

Differences A, B are significant $(\mathbf{P}<\mathbf{0 . 0 5})$ to compare rows, ca: cancer; R.M.: resection margin

While There was no significant difference $(\mathrm{P}<0.05)$ in positive $\mathrm{Bcl}-2$ expression of the cancerous tissue between those 3 types of colorectal cancer but there was significant difference $(\mathrm{P}<0.05)$ in positive $\mathrm{Bcl}-2$ expression of the resection margin tissue between adenocarcinoma and signet ring Table (6).

Table (6): The correlation between all types of colorectal cancer according to the Bcl-2 positive expression.

\begin{tabular}{|c|c|c|c|c|}
\hline & & Bcl-2 pos & expr. \% Mea & \& Cancer type \\
\hline & & $\mathrm{AC}$ & MUCINOUS & SIGNET RING \\
\hline & & $\mathbf{A}$ & $\mathbf{A}$ & $\mathbf{A}$ \\
\hline Cancer & Positive & $33.19 \pm 2.15$ & $30.60 \pm 5.05$ & $29.33 \pm 5.40$ \\
\hline R maro & & $\overline{\mathbf{A}}$ & $\mathbf{A} \overline{\mathbf{B}}^{*}$ & $\mathbf{B}^{*}$ \\
\hline R.marg & Positive & $16.19 \pm 1.37$ & $12.00 \pm 1.71$ & $7.33 \pm 2.70$ \\
\hline
\end{tabular}

Differences A, B are significant $(\mathbf{P}<\mathbf{0 . 0 5})$ to compare rows, ca: cancer; R.M.: resection margin. 


\section{Correlation between positive Bcl-2 expression and the grading of the colorectal cancer cells}

There was a significant difference $(\mathrm{P}<0.05)$ in the positivity of the $\mathrm{Bcl}-2$ expression between the cancerous tissue and resection margin inside all the 3 types types of differentiation Table (7).

Table (7): The positive Bcl-2 expression in all colorectal cancer grades

\section{Bcl-2 Positive expr. \% Mean+SE \& Differentiation of cells}

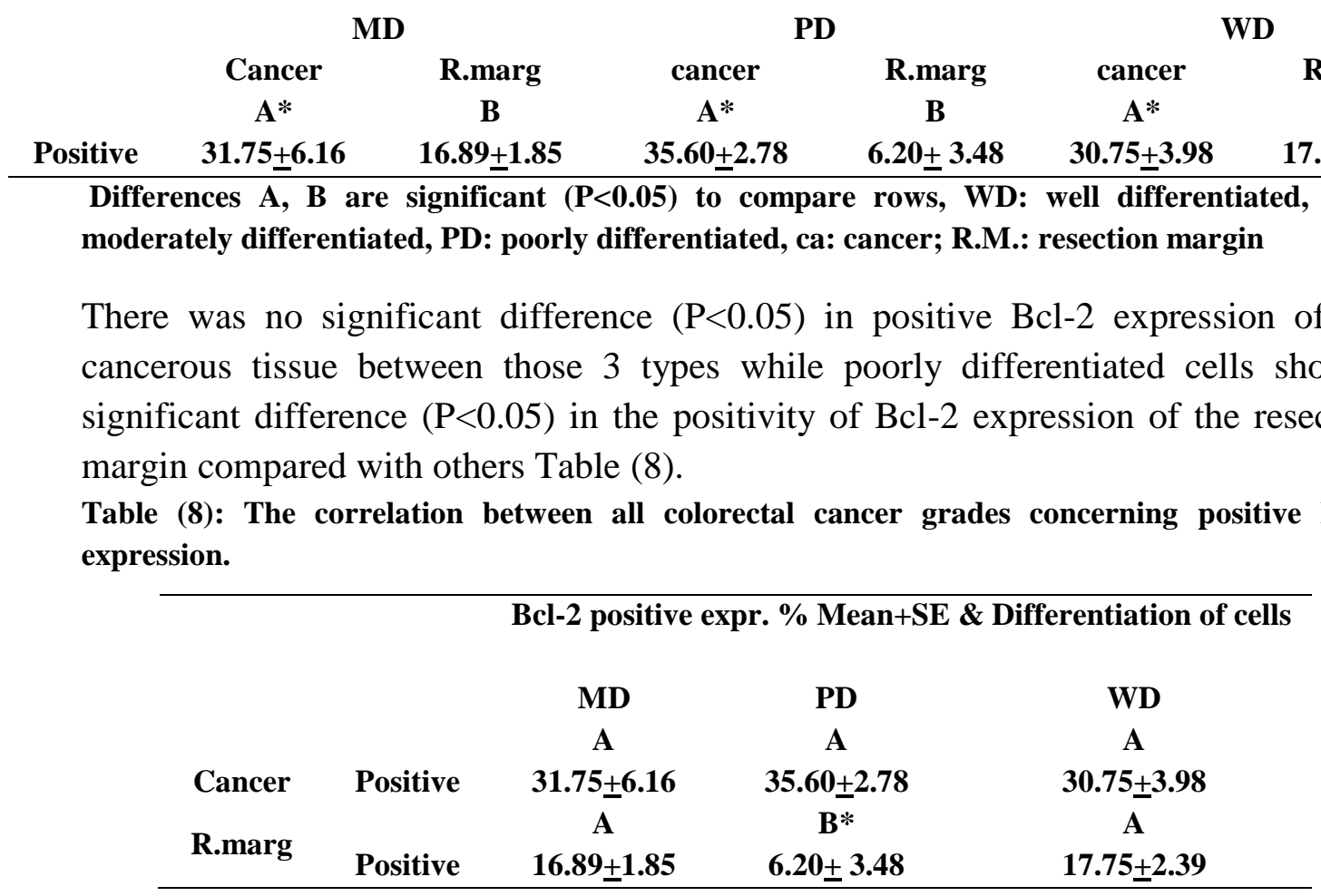

Differences $A, B$ are significant $(\mathbf{P}<0.05)$ to compare rows, WD: well differentiated, MD: moderately differentiated, PD: poorly differentiated ca: cancer; R.M.: resection margin.

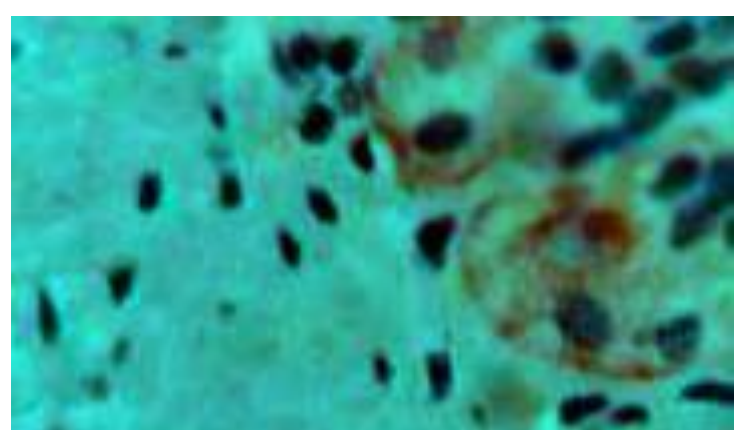

Figure (1): Immunohistochemical staining in colorectal cancer sections. Bcl-2 cytoplasmic positive Immunostaining by peroxidase/DAB (brown) counterstained with hematoxylin 40x.

\section{Discussion}

In the gastrointestinal tract the physiologic expression of Bcl-2 protein is confined to the stem cells and the proliferative zone, i.e., the lower crypt of the intestinal or colonic mucosa $[10,11]$.Obviously, the function of $\mathrm{Bcl}-2$ here is to protect the 
regenerative epithelial compartment from cell death. Although shedding of differentiated and mature cells to the luminal surface is the major mechanism of cellular loss in the gastrointestinal tract, apoptosis seems to be triggered before mechanical cell elimination takes place. Thus, apoptosis also contributes physiologically to the normal intestinal cell turn-over $[12,13,14,15,16]$.

Bcl-2 is strongly expressed in most colorectal adenomas and carcinomas, with the highest incidence in adenomas. Bcl-2 expression is evidently characteristic of early stages in colorectal carcinogenesis followed by other genetic changes (like TP53 loss). Thus, apart from genetic changes leading to deregulation of proliferation, the inhibition of apoptosis by bcl-2 expression may also promote tumor growth at this stage of carcinogenesis [17].

In this study, there was a significant positive expression of $\mathrm{Bcl}-2$ in the cancerous tissue comparing to the resection margin which revealed a better clinical outcome and it would appear that the role of Bcl-2 is probably more important in the early development of colorectal tumors than in later tumor progression according to many studies concerning colorectal cancers and other type of cancers like: non small cell lung cancer, B-cell lymphomas, almost all thyroid cancers and ovarian carcinomas $[17,18]$.

The correlation between high proliferation rate and a high rate of apoptosis in carcinomas suggests that an excess of putatively inappropriate or conflicting growth signals may also trigger apoptosis [17, 19, 20].

Others suggested that there is a shifting from expression of the anti-apoptotic Bcl-2 to Bcl-xl which with the expression of the c-Myb predict a poor prognosis [22]. By time, P53 will act as a transcriptional factor that has the capacity to alter the expression ratios of Bcl-2 and Bcl-xL (down-regulated) and Bax (up-regulated) in favor of apoptosis [21].

Also, Bcl-2 function may be sacrificed for another advantage (such as loss of DCC which is an oncosuppressor gene on chromosome 18). These data dovetail, to some degree, with the data showing a correlation between loss of expression of DCC protein and poor prognosis as both the Bcl-2 and DCC genes occur on chromosome $18 \mathrm{q} 21[20]$.

Finkel and his colleagues provided us with another theory about how Bcl-2 expression could be a predictor for a good prognosis in colorectal cancer as well as a target for therapy by showing that Bcl-2 suppress autophagy which in turn will made the tumor cell a senescent one and we can here explain why the positive $\mathrm{Bcl} 2$ expression has a good outcome in colorectal cancer patients as well as it's a prognostic marker [22,23]. Other researchers postulated that Loss of pSer70 Bcl-2 expression is closely linked to biological aggressiveness in colorectal tumors and represents a statistically significant molecular index for prognosis of patients with these tumors [24].

Most of the articles concerning positive $\mathrm{Bcl} 2$ expression and colorectal tumor site association mentioned no correlation [3,5,20,21,22,23]. While in our study the correlation existed between different sites especially between the hepatic flexure and rectum which can be explained that the cancers at or below the peritoneal reflection 
(rectosigmoide/rectum) are more aggressive compared with those above the reflection (colon) and the worse prognosis for patients with lesions in the right colon [25].

According to the type of colorectal cancers, it was observed that there was a significant correlation of the positive Bcl-2 expression between the cancerous tissue and resection margin inside the three types of colorectal cancer which it was not between the three types and also mentioned in other studies [3].

The results concerning the bcl-2 positive expression correlated to grading of colorectal cancers showed insignificant results which can be seen also in other studies $[3,17,23,24]$.

\section{References}

1. Boyle, P. and Leon, M. (2002). Epidemiology of colorectal cancer. Br. Med. Bull. ,64 (1): $1-25$.

2. Iraqi cancer board. (2008). Iraqi cancer regestry2004. Ministry of Health. Iraq.

3. Dursun, A.; Poyraz, A.; Suer, O.; Sezer, C. and kyol, G. (2001). Expression of Bcl2 and c-ErB-2 in colorectal neoplasia. Pathology Oncology Research.7:24-27.

4. Tsamandas, A.; Kardamakis, D.; Petsas, T.; Zolota, V.; Vassillol, V.; Matatsoris, T.; Kalofonos, H.;Vagianos ,C. and Scopa, C. (2007). Bcl-2, Bax and p53 Expression in Rectal Adenocarcinoma. Correlation with Classic Pathologic Prognostic Factors and Patients' Outcome. In Vivo. 21(1):113-8.

5. Ilyas, M. ; Hao, X.; Wilkinson, K.; Tomlinson, I .; Abbasi, A.; Forbes , A.; Bodmer ,W. and Talbot, I. (1998). Loss of Bcl-2 expression correlates with tumor Recurrence in colorectal cancer. Gut. 43:383-387.

6. Hague, A.; Moorghen, M.; Hicks, D.; et al. (1994). BCL-2 expression in human colorectal adenomas and carcinomas. Oncogene. 9:3367-70.

7. Reed, JC. (1994). Bcl-2 and the regulation of programmed cell death. J. Cell Biol.124:1-6.

8. Watson, A.J.; Merritt, A.J.; Jones, L.S.; et al. (1996). Evidence of reciprocity of bcl-2 and p53 expression in human colorectal adenomas and carcinomas. Br. J. Cancer .73:889-95.

9. Sulkowska, M.; Famulski, W.;. Sulkowski, S.; Reszec, J.; Koda, M.; Baltaziak, M. and L. Kan'czuga-Koda. (2003). Correlation between Bcl-2 Protein Expression and Some Clincopathological Features of Oral Squamous Cell Carcinoma. Pol. J .Pathol, 1:49-52.

10. Hockenbery, DM. ; Zutter M. ; Hickey W. ; Nahm M. and Korsmeyer SJ. (1991). bcl2 protein is topographically restricted in tissues characterized by apoptotic cell death. Proc. Nut. Acad Sci USA. 88:6961-6965.

11. LeBrun, D.P.; Warnke R.A. and Cleary M.L. (1993). Expression of bcl-2 in fetal tissues suggests a role in morphogenesis. Am J Path. 142:743-53.

12. Eastwood, GL. (1977). Gastrointestinal epithelial renewal. Gastroenrerology. 72:96275.

13. Eastwood, GL. (1992). Epithelial renewal in premalignant conditions of the gastrointestinal tract: A review. / Clirz Gasrroenrerol; 14(Suppl. i):S29-33.

14. Gavrieli, Y.; Sherman Y. and Ben-Sasson SA. (1992). Identification of programmed cell death in situ via specific labeling of nuclear DNA fragmentation. J.Cell Riol. 119:493-501. 
15. Ansari, B.; Coates P.J. ; Greenstein B.D. and Hall P.A. (1993). In situ end labeling detects DNA strand breaks in apoptosis and other physiological and pathological states. J Path170:1-8.

16. Benedetti A. ; Mancini R.; Marucci L.; Paolucci F.; Jezequel A.M.; Orlandi F. (1990). Alimentary tract and pancreas: Quantitative study of apoptosis in normal rat gastroduodenal mucosa. J. Gustroenterol Hepatol. 5:369-74.

17. Baretton, G.B.; Diebold, J.; Christoforis, G.; Vogt, M.; Miiller, C.; Dopfer, K.; Schneiderbanger, K.; Schmid, M. and Lohrs, U. (1996). Apoptosis and lmmunohistochemical bcl-2 Expression in Colorectal Adenomas and Carcinomas Aspects of Carcinogenesis and Prognostic Significance. Cancer. 77:255-264.

18. Ofner, D.; Riehemann K.; Maier H.; Riedmann B.; Nehoda H.; Totsch M.; Bocker W.; Jasani B. and Schmid K.W. (1995). Immunohistochemical detectable Bcl-2 expression in colorectal carcinoma: correlation with tumor stage and patient survival. Brit. J. Cancer 72:11-16.

19. Barreton, G.B. ; Diebold, J. ; Christoforis ,G. ; Vogt ,M. ; Muller ,C. ; Dopfer, K. ; Schneiderbanger, K. ; Schmidt, M. and Lohrs ,U. (1996). Apoptosis and Immunohistochemical Bcl-2 expression in colorectal adenomas and carcinomas. Cancer 77: 255-264.

20. Jiang, M. and Milner, J. (2003). Colorectal cancer cells Bcl-2 constitutively suppresses p53-dependent apoptosis in colorectal cancer cells. Genes Dev. 17: 832-837.

21. Biroccio, A.; Benassi, B.; Dagnano, I.; Dangelo, C.; Buglioni, S.; Mottolese, M.; Ricciotti, A.; Citro, G.; Cosimelli, M.; Ramsay, R.B.; Calabretta, B. and upi, G. (2001). c-Myb and Bcl-x overexpression predicts poor prognosis in colorectal cancer. American journal of pathology. 4:1289-1299.

22. Finkel, T.; Serrano, M. and Blasco, M. A. (2007). The common biology of cancer and ageing. Nature. 448:767-774.

23. Zavrides, H. ; Zizi-Sermpetzoglou, A.; Elemenoglou, I.; Papatheofanis, I. ; Peros,G.; Athanasas, G. and Panousopoulos, D. (2006). Immunohistochemical expression of bcl-2 in UICC stage I and III colorectal carcinoma patients: correlation with c-erbB-2, p53, ki-67, CD44, laminin and collagen IV in evaluating prognostic significance. Pol. J. Pathol. 57:149-59.

24. Eisaku, K .; Takayoshi, M.; Masao, S.; Toshikazu, K.; Hiromi, I.; Shin-ichi, N.; Takehiro, T.; Nobuya, O.; Koichi, I.; Takashi,O.; Hiroyuki, Y.; Futoshi, S. and Tadashi, Y. (2005). Expression of Phosphorylated Ser70 of Bcl-2 Correlates with Malignancy in Human Colorectal Neoplasms .Clin. Cancer Res. 11:7255-7263.

25. V.T., De Vita; Hellman, J.S. and Rosenberg, S.A. (1997). Cancer:principls and practice of oncology. $5^{\text {th }}$ ed., Lippincott-Raven. 